\title{
Cyanobacterial Heterocysts
}

\author{
Krithika Kumar' ${ }^{2}$, Rodrigo A. Mella-Herrera ${ }^{1,2}$, and James W. Golden ${ }^{1}$ \\ ${ }^{1}$ Division of Biological Sciences, University of California-San Diego, La Jolla, California 92093 \\ ${ }^{2}$ Department of Biology, Texas A\&M University, College Station, Texas 77843 \\ Correspondence: jwgolden@ucsd.edu
}

\begin{abstract}
Many multicellular cyanobacteria produce specialized nitrogen-fixing heterocysts. During diazotrophic growth of the model organism Anabaena (Nostoc) sp. strain PCC 7120, a regulated developmental pattern of single heterocysts separated by about 10 to 20 photosynthetic vegetative cells is maintained along filaments. Heterocyst structure and metabolic activity function together to accommodate the oxygen-sensitive process of nitrogen fixation. This article focuses on recent research on heterocyst development, including morphogenesis, transport of molecules between cells in a filament, differential gene expression, and pattern formation.
\end{abstract}

$\mathrm{O}$ rganisms composed of multiple differentiated cell types can possess structures, functions, and behaviors that are more diverse and efficient than those of unicellular organisms. Among multicellular prokaryotes, heterocystforming cyanobacteria offer an excellent model for the study of cellular differentiation and multicellular pattern formation. Cyanobacteria are a large group of Gram-negative prokaryotes that perform oxygenic photosynthesis. They have evolved multiple specialized cell types, including nitrogen-fixing heterocysts, sporelike akinetes, and the cells of motile hormogonia filaments. Of these, the development of heterocysts in the filamentous cyanobacterium Anabaena (also Nostoc) sp. strain PCC 7120 (hereafter Anabaena PCC 7120) has been the best studied. Heterocyst development offers a striking example of cellular differentiation and developmental biology in a very simple form:
Filaments are composed of only two cell types and these are arrayed in a one-dimensional pattern similar to beads on a string (Figs. 1 and 2).

Many cyanobacterial species are capable of nitrogen fixation. However, oxygenic photosynthesis and nitrogen fixation are incompatible processes because nitrogenase is inactivated by oxygen. Cyanobacteria mainly use two mechanisms to separate these activities: a biological circadian clock to separate them temporally, and multicellularity and cellular differentiation to separate them spatially. For example, the unicellular Cyanothece sp. strain ATCC 51142 stores glycogen during the day and fixes nitrogen at night (Toepel et al. 2008), whereas the filamentous Trichodesmium erythraeum IMS101 fixes nitrogen during the day in groups of specialized cells (Sandh et al. 2009). Heterocyst-forming cyanobacteria differentiate highly specialized cells

Editors: Lucy Shapiro and Richard Losick

Additional Perspectives on Cell Biology of Bacteria available at www.cshperspectives.org

Copyright (C) 2010 Cold Spring Harbor Laboratory Press; all rights reserved; doi: 10.1101/cshperspect.a000315

Cite this article as Cold Spring Harb Perspect Biol 2010;2:a000315 

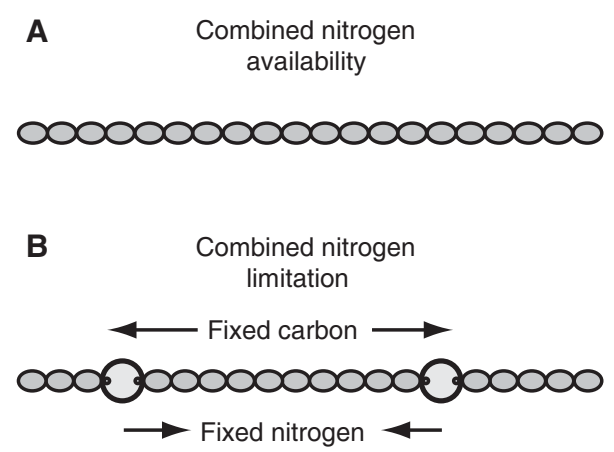

Figure 1. Heterocyst development in Anabaena PCC 7120. (A) Anabaena PCC 7120 grown in medium containing a source of combined nitrogen grows as filaments of photosynthetic vegetative cells. $(B)$ In the absence of combined nitrogen, heterocysts differentiate at semiregular intervals, forming a developmental pattern of single heterocysts every 10 to 20 vegetative cells along filaments. Heterocysts are often larger than vegetative cells, have a thicker multilayered envelope, and usually contain cyanophycin granules at their poles adjacent to a vegetative cell.

to provide fixed nitrogen to the vegetative cells in a filament.

In the presence of a source of combined nitrogen such as nitrate or ammonium, Anabaena PCC 7120 grows as long filaments containing hundreds of photosynthetic vegetative cells. In the absence of combined nitrogen, it produces heterocysts, which are terminally differentiated nitrogen-fixing cells that form at semiregular intervals between stretches of vegetative cells to produce a multicellular pattern of single heterocysts every ten to twenty vegetative cells along filaments (Figs. 1 and 2). Some heterocyst-forming cyanobacteria show different regulation or display different developmental patterns but these topics are beyond the scope of this article. Heterocyst development involves integration of multiple external and internal signals, communication between the cells in a filament, and temporal and spatial regulation of genes and cellular processes. The study of heterocyst development in Anabaena PCC 7120 has proven to be an excellent model for the study of cell fate determination, pattern formation, and differential gene expression during prokaryotic multicellular evelopment. Various aspects of heterocyst development, signaling, and regulation have been the subject of several recent reviews (Meeks and Elhai 2002; Forchhammer 2004; Herrero et al. 2004; Zhang et al. 2006; Aldea et al. 2008; Zhao and Wolk 2008).

Although beyond the scope of this article, it should be noted that cyanobacteria have recently attracted increased attention because of their important roles in environmental carbon and nitrogen fixation (Montoya et al. 2004), and their potential for providing renewable chemicals and biofuels (Dismukes et al. 2008).

\section{CELLULAR DIFFERENTIATION, MULTICELLULARITY, AND TRANSPORT ALLOW SPECIALIZED FUNCTIONS}

Cyanobacteria have a Gram-negative cell wall that includes two distinct membranes, the plasma membrane and an outer membrane, and a peptidoglycan layer, which is thicker than in other Gram-negative bacteria, sandwiched between these two membranes (Hoiczyk and Hansel 2000). External to the cell wall is a carbohydrate-enriched glycocalyx that can have different relative amounts of three recognizable layers: a closely associated sheath, a defined capsule, and loosely associated slime. These layers protect the cells from desiccation and presumably from phages and predators. Cyanobacteria contain extensive internal thylakoid membranes (Fig. 2), which are the site of photosynthetic reactions, but these will not be considered further here.

Heterocysts are typically distinguishable from vegetative cells by their somewhat larger and rounder shape, diminished pigmentation, thicker cell envelopes, and usually prominent cyanophycin granules at poles adjacent to vegetative cells (Fig. 2). The additional envelope layers surrounding heterocysts help to protect the enzyme nitrogenase from oxygen (Fay 1992). For details of the heterocyst cell wall and envelope, readers are referred to recent reviews (Awai et al. 2009; Nicolaisen et al. 2009; Pereira et al. 2009). Mature heterocysts provide the microoxic environment required for nitrogen fixation, spatially separating oxygen-evolving photosynthesis in vegetative 


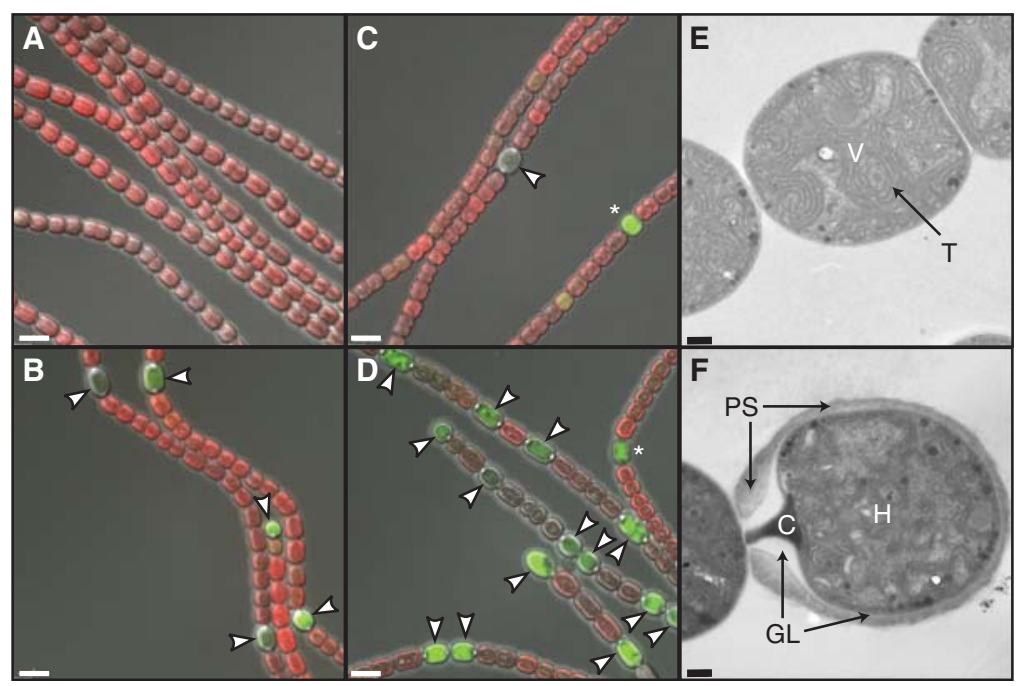

Figure 2. Heterocyst development in Anabaena PCC 7120. Filaments of the wild type carrying a patS-gfp reporter grown in medium containing nitrate are composed of vegetative cells $(A)$, and have undergone heterocyst development $1 \mathrm{~d}$ after transfer to medium without combined nitrogen $(B)$. A patS mutant strain carrying the same patS-gfp reporter grown in media containing nitrate contains a small number of heterocysts $(C)$, and $1 \mathrm{~d}$ after transfer to medium without combined nitrogen shows a higher than normal frequency of heterocysts and an abnormal developmental pattern $(D) .(A, B, C, D)$ Merged DIC (grayscale), autofluorescence of photosynthetic pigments (red), and patS-gfp reporter fluorescence (green) microscopic images; arrowheads indicate heterocysts; asterisks indicate proheterocysts; size bar, $5 \mu \mathrm{m}$. (E, F) Transmission electron micrographs of wild-type vegetative cells $(\mathrm{V})$ and a heterocyst $(\mathrm{H})$ at the end of a filament; T, thylakoid membranes; PS, polysaccharide layer; GL, glycolipid layer; C, polar cyanophycin granule; size bar, $0.2 \mu \mathrm{m}$.

cells from nitrogen fixation. Differentiating cells undergo many metabolic and morphological changes (Golden and Yoon 1998). Oxygen-producing photosystem PSII is dismantled during differentiation and heterocysts show an increased rate of respiration (Wolk et al. 1994). Morphological changes include the deposition of two additional envelope layers around the heterocyst: an inner "laminated" layer composed of two heterocyst-specific glycolipids (HGL) and an outer polysaccharide layer (HEP) (Cardemil and Wolk 1979; Cardemil and Wolk 1981; Nicolaisen et al. 2009). The heterocyst envelope polysaccharide layer is sometimes subdivided into a well-defined homogeneous inner layer and an external fibrous layer.

Heterocysts and vegetative cells are mutually interdependent. Because they lack photosystem II and carbon fixation, heterocysts are dependent on vegetative cells for a source of reductant and carbon, which is probably partially supplied as sucrose (Cumino et al. 2007; Marcozzi et al. 2009). In Anabaena PCC 7120, vegetative cells must also supply glutamate to heterocysts, which convert it to glutamine and other amino acids (Martin-Figueroa et al. 2000). In return, vegetative cells obtain fixed nitrogen in the form of amino acids from the heterocysts (Meeks and Elhai 2002). The temporal and spatial distributions of fixed carbon and nitrogen were studied using high-resolution nanometer-scale secondary ion mass spectrometry (NanoSIMS), in Anabaena oscillarioides (Popa et al. 2007). Newly fixed nitrogen is rapidly exported from heterocysts and distributed to nearby vegetative cells.

The exchange of metabolites and intercellular signals that control the regulated spacing of the heterocysts require movement of molecules between cells along a filament, possibly through a continuous periplasm (Flores et al. 2006). According to this model, molecules exported from one cell would diffuse through the 
K. Kumar, R.A. Mella-Herrera, and J.W. Golden

periplasm and then be taken up by other cells along a filament. It was recently shown that GFP expressed from the patS promoter, which is expressed at a low basal level in vegetative cells and strongly up-regulated in differentiating heterocysts, and targeted to the periplasm by a cleavable twin-arginine signal peptide, could diffuse through the heterocyst periplasm to nearby vegetative cells (Mariscal et al. 2007). GFP attached to the cytoplasmic membrane was only seen in heterocysts and not in adjacent vegetative cells. However, another group found that GFP targeted to the periplasm of vegetative cells or heterocysts using different cell-type specific promoters (P-hepA, P-patB, or P-rbcL) and the signal sequence of the Escherichia coli TorA protein attached to GFP showed no intercellular diffusion from one cell to the next (Zhang et al. 2008). The exported GFP diffused around individual cells but not beyond the cell borders. Although it is unclear why these two research groups came to different conclusions, it may be because of the different signal sequences that were used. The data obtained by Zhang et al. could be the result of a failure to cleave the TorA signal peptide from the GFP reporter, which could result in the GFP being anchored to the membrane or localized to the space on the inner side of the peptidoglycan layer. Electron micrographs of Anabaena PCC 7120 intercellular junctions appear to show an intact peptidoglycan layer around each cell and sometimes a distinct "junctional space" between these peptidoglycan layers (Fig. 3) is observed, which could be a barrier for secreted large molecules.

Recent data support the exchange of molecules through intercellular junctions or channels directly connecting the cytoplasm of adjacent cells (Mullineaux et al. 2008). Calcein, a small fluorescent molecule loaded into the cytoplasm of cells, was found to quickly diffuse between cells. Electron micrographs suggest the existence of connections between adjacent cells named microplasmodesmata (Fig. 3) (Giddings and Staehelin 1978; Giddings and Staehelin 1981). The microplasmodesmata may be channels formed by protein oligomers, and FraG (SepJ) has been suggested as a candidate channel forming protein (Flores et al. 2007;

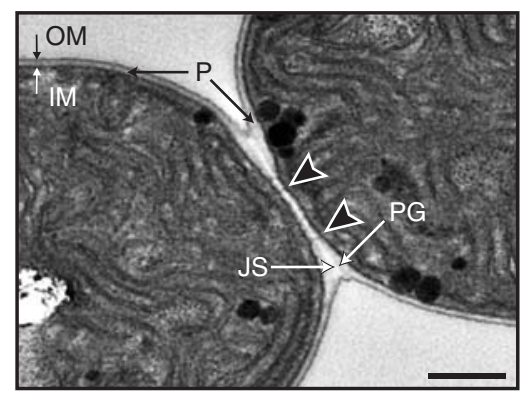

Figure 3. Transmission electron micrograph of the junction between two vegetative cells. Arrowheads indicate microplasmodesmata, which are potential cell-to-cell channels. Note the "junctional space" between the cell wall peptidoglycan layers of the two cells, which may indicate a partial barrier between the periplasmic compartments of adjacent cells. IM, inner membrane; OM, outer membrane; P, periplasm; PG, peptidoglycan cell wall; JS, junctional space. Size bar, $0.5 \mu \mathrm{m}$.

Nayar et al. 2007). FraG has a large extracytoplasmic domain that may be involved in spanning the cell wall and bridging the gap between adjacent cells (Flores et al. 2007). Localization studies with a FraG-GFP reporter showed that it is expressed in both cell types and that it is localized at intercellular septa (Flores et al. 2007). fra G mRNA levels increase after nitrogen depletion and fraG null mutants are unable to differentiate heterocysts completely (Flores et al. 2007; Nayar et al. 2007). The diffusion of calcein required FraG, suggesting that FraG could be the channel forming protein connecting the cytoplasm of two adjacent cells (Mullineaux et al. 2008).

\section{GENE EXPRESSION AND MORPHOGENESIS DURING HETEROCYST DEVELOPMENT}

The timeline of heterocyst development begins with sensing combined-nitrogen limitation and culminates with nitrogen fixation in the mature heterocyst. Heterocyst development is complete in about 20 hours at $30^{\circ} \mathrm{C}$ and involves cellular differentiation of selected vegetative cells into heterocysts and less obvious changes in gene expression and metabolism in the remaining vegetative cells. Several studies using DNA microarray methods show global changes 
in gene expression after nitrogen step-down (Ehira et al. 2003; Sato et al. 2004; Ehira and Ohmori 2006b; Campbell et al. 2007). The process of differentiation is reversible if a source of combined nitrogen or the inhibitory PatS pentapeptide is added within 9-12 hours after nitrogen deprivation, after which point the cells are committed to forming heterocysts (Fig. 4) (Thiel and Pratte 2001; Yoon and Golden 2001).

\section{Initiation and Early Stages of Heterocyst Development}

The presence of a source of combined nitrogen such as ammonium or nitrate inhibits the differentiation of heterocysts. In cyanobacteria, 2-oxoglutarate, an intermediate in the Krebs cycle, constitutes the signal for nitrogen deprivation (Laurent et al. 2005; Zhang et al. 2006). The Krebs cycle in cyanobacteria is incomplete because of the lack of 2-oxoglutarate dehydrogenase. As a result, 2-oxoglutarate's main function is to serve as a precursor in a variety of biosynthetic reactions. It is the primary carbon skeleton for incorporation of ammonium and is considered the metabolic junction between carbon and nitrogen balance in cyanobacteria (Muro-Pastor et al. 2001; Vazquez-Bermúdez et al. 2003; Muro-Pastor et al. 2005). Nitrogenlimiting conditions result in an increase in the levels of 2-oxoglutarate. An artificial analog of 2-oxoglutarate, 2,2-difluoropentanoic acid, DFPA, added to medium resulted in heterocyst development even in the presence of ammonium, showing that 2-oxoglutarate plays a key role in controlling heterocyst development (Laurent et al. 2005).

NtcA, a transcriptional regulator belonging to the CRP (cyclic AMP receptor protein) family of proteins, senses 2-oxoglutarate levels (Fig. 5). The protein is conserved in all cyanobacteria and regulates a number of genes involved in carbon and nitrogen metabolism (Herrero et al. 2004; Marcozzi et al. 2009). In Anabaena PCC 7120, NtcA is required for the expression of the genes in pathways for ammonium and nitrate assimilation, as well as heterocyst development (Wei et al. 1993; Ramasubramanian et al. 1994). The $n t c A$ gene is induced soon after nitrogen deprivation and is autoregulated (Ramasubramanian et al. 1994; Ramasubramanian et al. 1996; Muro-Pastor et al. 2002). $n t c A$ mutants are unable to use nitrate as the sole source of nitrogen and are blocked from initiating heterocyst development (Frias et al. 1994; Wei et al. 1994). Genes that are activated by NtcA typically have the consensus binding site TGTA- $\left(\mathrm{N}_{8}\right)$-TACA centered at -41.5 nucleotides upstream of the transcription start point (TSP) (Herrero et al. 2004). The DNA binding activity of NtcA is enhanced in the presence of 2-oxoglutarate, and 2-oxoglutarate is necessary for transcriptional activation by NtcA (Tanigawa et al. 2002; Vazquez-Bermúdez et al. 2002). Additionally, DFPA, the synthetic analogue of 2-oxoglutarate, stimulates DNA binding activity of NtcA in vitro (Laurent et al. 2005; Chen et al. 2006).

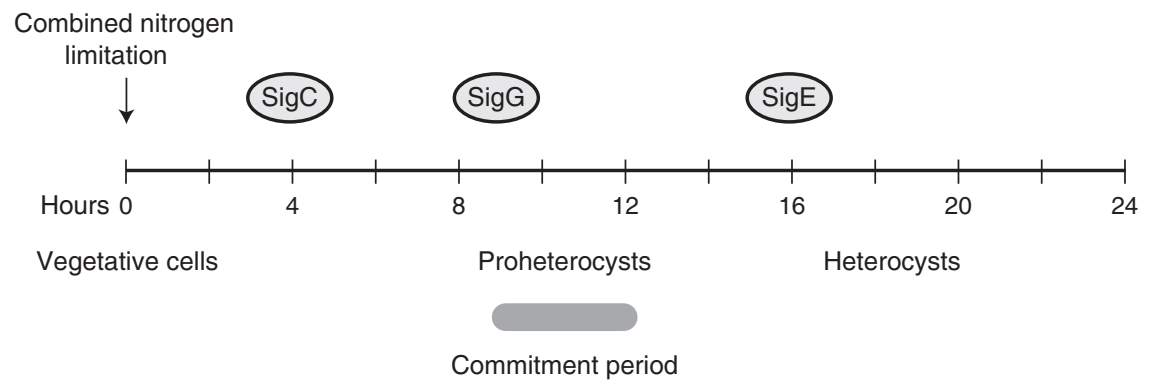

Figure 4. Developmentally regulated $\sigma$ factors in Anabaena PCC 7120. The positions of the $\sigma$ factor icons mark the times that GFP transcriptional reporters for the $\sigma$ factor genes are up-regulated during heterocyst development. Filaments are composed of vegetative cells before nitrogen limitation. Immature proheterocysts are observed during approximately the same period of time when cells become committed to complete differentiation. Mature heterocysts are present by $20 \mathrm{~h}$. See text for details. 
K. Kumar, R.A. Mella-Herrera, and J.W. Golden

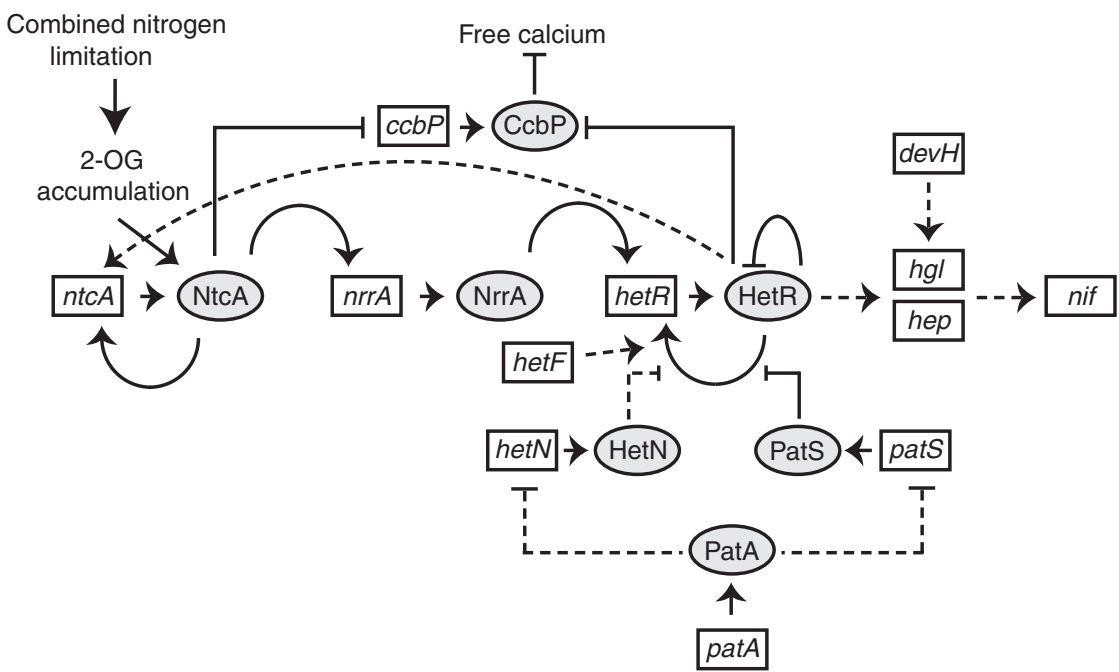

Figure 5. Model of regulatory interactions during heterocyst development. For clarity, the figure shows only selected genes, proteins, and events. Open boxes represent genes and gray ovals represent proteins. Lines ending in arrows and bars indicate positive and negative interactions, respectively. Dashed lines represent indirect and/or unknown interactions or missing steps. Short arrows are between genes and their products. See the text for details.

HetR is a master regulator of heterocyst development and plays a key role in differentiation and pattern formation (Buikema and Haselkorn 1991b). Null mutants of hetR fail to produce heterocysts, and overexpression of het $R$ (Buikema and Haselkorn 1991a; Buikema and Haselkorn 2001), and particular point mutants (Khudyakov and Golden 2004) result in increased heterocyst frequency. het $R$ is one of the earliest genes induced in differentiating cells and is positively autoregulated (Fig. 5) (Black et al. 1993; Buikema and Haselkorn 2001). Transcription of hetR increases as early as 30 minutes after nitrogen deprivation, and by 3.5 hours, expression is confined to spaced foci arranged in a pattern similar to that of differentiating cells.

HetR protein is a serine type protease that has autoprotease activity and DNA binding activity that requires formation of a HetR homodimer (Zhou et al. 1998; Huang et al. 2004). The heterocyst inhibitory peptide PatS interferes with HetR DNA-binding activity in vitro (Huang et al. 2004). Mutations that affect these activities block heterocyst development at an early stage; however, the role of particular amino acid residues is unclear (Dong et al. 2000; Risser and Callahan 2007). A het $R_{R 223 W}$ point mutant is insensitive to the main inhibitory signals of pattern formation, PatS, and HetN (Fig. 5), and produces a conditionally lethal phenotype because of complete differentiation under nitrogen limiting conditions (Khudyakov and Golden 2004).

Expression of $n t c A$ and het $R$ show a mutual dependency during heterocyst development (Muro-Pastor et al. 2002). hetR is not induced in an $n t c A$ mutant and $n t c A$ expression is transiently induced in a HetR-dependent manner (Frias et al. 1994; Muro-Pastor et al. 2002). Expression of some genes involved in the developmental process is dependent on both ntcA and hetR; however, in some cases, the dependency is probably because of the interdependent up-regulation of hetR and $n t c A$ (Hebbar and Curtis 2000; Fiedler et al. 2001; Valladares et al. 2004). NrrA, a response regulator, has been identified as the regulatory link between NtcA and HetR (Fig. 5) (Ehira and Ohmori 2006a). $n r r A$ is transcribed in differentiating cells within 3 hours after nitrogen deprivation and is directly dependent on NtcA (Ehira and Ohmori 2006b; Muro-Pastor et al. 2006). Earlier work on the transposon reporter strain TLN14, now known to be a fusion to the nrrA gene, showed 
rapid induction 1 hour after nitrogen stepdown (Cai and Wolk 1997). An nrrA mutant strain shows a delay in heterocyst development caused by a delay in accumulation of HetR, and extra copies of $n r r A$ result in increased expression of $h e t R$, and thus, increased heterocyst frequency (Ehira and Ohmori 2006a; Ehira and Ohmori 2006b).

In Anabaena PCC 7120, the calcium-binding luminescent protein aequorin was used to detect an increase in intracellular calcium levels after nitrogen deprivation (Torrecilla et al. 2004). The $\mathrm{Ca}^{++}$reporter obelin was used to show a 10 -fold higher $\mathrm{Ca}^{++}$concentration in heterocysts compared with vegetative cells at 4 hours after nitrogen deprivation (Zhao et al. 2005). The increase in $\mathrm{Ca}^{++}$concentrations is because of the decreased expression of $c c b P$, which encodes a calcium sequestering protein, CcbP (Fig. 5) (Zhao et al. 2005). ccbP message is down-regulated in differentiating cells and absent in mature heterocysts. Inactivation of $c c b P$ causes a multiple-contiguous-heterocyst (Mch) phenotype and overexpression inhibits heterocyst development. It has been hypothesized that a regulatory pathway consisting of HetR, CcbP, and NtcA controls intracellular free calcium; HetR specifically degraded CcbP in a calcium-dependent manner, and $c c b P$ downregulation required 2-oxoglutarate-dependent binding of NtcA to its promoter (Shi et al. 2006). The increase in $\mathrm{Ca}^{++}$in differentiating cells is thought to be important for HetR's $\mathrm{Ca}^{++}$-dependent serine protease and/or other $\mathrm{Ca}^{++}$-dependent proteolytic activities.

HetF influences heterocyst development by a positive effect on hetR expression (Fig. 5) (Wong and Meeks 2001; Risser and Callahan 2008). In mutants of hetF, expression of hetR was not localized to heterocysts and initiation of heterocyst development was not seen (Wong and Meeks 2001). Overexpression of hetF produces a multiple-contiguous-heterocyst phenotype, but only in the absence of combined nitrogen (Wong and Meeks 2001). Like HetR, HetF is likely to be a protease (Risser and Callahan 2008). An elegant mosaic analysis was used to show that HetF is required specifically in cells that differentiate (Risser and
Callahan 2008). However, it is also thought that HetF plays a role in restricting hetR expression and the accumulation of HetR protein to differentiating cells (Wong and Meeks 2001).

Like hetF, patA also influences heterocyst development via a positive effect on hetR expression, but its effect is related to pattern formation (Fig. 5) (Liang et al. 1992; Risser and Callahan 2008). The patA gene encodes a response regulator similar to the CheY protein, which functions as a phosphorylation-activated switch (Liang et al. 1992). patA mutants form heterocysts almost exclusively at the ends of filaments. This mutant phenotype is maintained even when het $R$ is overexpressed in a patA mutant background, suggesting that pat $A$ acts downstream of hetR (Liang et al. 1992; Buikema and Haselkorn 2001). It is possible that PatA influences heterocyst development by attenuating the negative effects of the main inhibitory signals of heterocyst pattern formation, PatS and HetN (Orozco et al. 2006).

The het $C$ gene, which encodes a member of the family of ATP-binding cassette type exporters, is required for an early step in the differentiation of heterocysts as observed by a $\mathrm{P}_{h e t C^{-}} g f p$ reporter, which showed an increase in expression in proheterocysts and heterocysts (Khudyakov and Wolk 1997; Muro-Pastor et al. 1999). A het $C$ mutant carrying a $\mathrm{P}_{\text {het }}-g f p$ reporter shows a pattern of weakly fluorescent cells that are blocked from further stages of development (Xu and Wolk 2001; Wang and Xu 2005). It is possible that the het $C$ mutant fails to complete an early step in morphogenesis of the envelope that then triggers a developmental checkpoint that prevents further differentiation.

Two novel genes, hetL and asr1734, have been shown to be involved in regulating heterocyst development, but their exact roles and biochemical functions remain unclear. HetL is a pentapeptide-repeat protein composed almost entirely of 40 tandem pentapeptide repeats forming 10 complete coils ( $\mathrm{Ni}$ et al. 2009). The het $L$ gene was isolated in a genetic screen designed to identify genes involved in PatS signaling (Liu and Golden 2002). Overexpression of het $L$ in a patS-overexpression strain allows heterocysts to form by bypassing the PatS 
inhibitory signal. Overexpression of hetL in the wild type produces a multiple-contiguous-heterocyst phenotype. hetL overexpression even induces partial heterocyst development in an $n t c A-$ null mutant. A hetL-null mutant shows normal heterocyst development and diazotrophic growth, indicating that het $L$ plays a nonessential role in heterocyst development.

The asrl734 gene is found in only heterocyst-forming cyanobacteria and a $\mathrm{P}_{a s r 1734^{-}} g f p$ reporter showed localized expression in proheterocysts and heterocysts after nitrogen stepdown. An asr 1734 knockout mutant shows elevated levels of $n t c A$ mRNA and forms 15\% heterocysts and a weak Mch phenotype in media without fixed nitrogen. Overexpression of asr1734 inhibits heterocyst development in the wild type and in two genetic backgrounds that stimulate heterocyst formation, a patS null and a het $R_{R 223 W}$ mutant, suggesting that Asr1734 acts downstream of PatS and HetR (Wu et al. 2007).

Cyclic-di-GMP signaling appears to be involved in heterocyst development. The all2874 gene, which encodes a diguanylate cyclase, is required for normal heterocyst development during growth under conditions of high light intensity (Neunuebel and Golden 2008). An all2874 mutant shows a significant reduction in heterocyst frequency and reduced vegetative cell size. An all2874 mutant strain carrying a $\mathrm{P}_{\text {pats }}-g f p$ transcriptional reporter did not show normal up-regulation of the reporter, indicating that the decrease in heterocyst frequency is because of an early block in differentiation.

\section{Heterocyst Cellular Differentiation Produces an Environment for Nitrogen Fixation}

The middle and later stages of heterocyst development are distinguished by structural and physiological changes. These changes begin with morphogenesis of the heterocyst envelope by the deposition of an outer polysaccharide layer and an inner glycolipid layer, which decrease the entry of oxygen into the heterocyst (Fig. 2) (Fay 1992). Mutants that lack the envelope polysaccharide or the glycolipid layer are unable to grow diazotrophically in the presence of air (Wolk et al. 1988; Wolk
1996; Fan et al. 2005; Huang et al. 2005; Nicolaisen et al. 2009).

Deposition of the external polysaccharide layer is one of the earliest morphological changes during heterocyst differentiation. DevR and HepK, which comprise a two component regulatory system, are involved in biosynthesis of the polysaccharide layer (Zhou and Wolk 2003). The hep genes hepA, hepB, and hepC, and a cluster of genes present around hepA are required for the deposition of the polysaccharide layer (Zhu et al. 1998; Huang et al. 2005; Wang et al. 2007).

The heterocyst glycolipid layer is assembled beneath the polysaccharide layer and is composed of fatty alcohols glycosidically linked to sugar residues. The $h g l B, h g l C, h g l D$, and $h g l E$ genes along with a cluster of nearby genes are required for the synthesis of these glycolipids (Campbell et al. 1997; Fan et al. 2005). DevH, a trans-acting regulatory protein, is required for the formation of the glycolipid layer, either by directly regulating the expression of the genes or indirectly through other gene products (Fig. 5) (Ramirez et al. 2005). The hglK gene is required for the localization of the glycolipids and may be directly involved in their deposition (Black et al. 1995). ORF all5341, named $h g l T$, is predicted to encode a glycosyl transferase and is required for the formation of the glycolipid layer (Awai and Wolk 2007).

Differentiation and maturation of heterocysts is dependent on DevBCA and $\mathrm{HgdD}$, which are thought to be a glycolipid exporter and outer membrane efflux tunnel, respectively (Fiedler et al. 1998; Moslavac et al. 2007a). The autolysin HcwA, which is presumably involved in cell wall remodeling, is required for heterocyst maturation (Zhu et al. 2001). The combination of autolysin activity and turgor pressure is presumably responsible for the slightly larger and rounder shape of heterocysts. The regulatory genes hepK, hepN, $h e n R$, and hepS are also required for normal heterocyst maturation (Lechno-Yossef et al. 2006).

Recent proteomic studies of the heterocyst and vegetative cell wall have identified proteins in the inner and outer membranes as a step toward understanding the dynamics of the cell wall proteome during cell differentiation 
(Moslavac et al. 2005; Moslavac et al. 2007b). Analysis of proteins of the outer membrane of vegetative cells and of heterocysts revealed a high similarity, suggesting that the relative protein concentrations within the outer membrane may vary between the two cell types but not the composition (Nicolaisen et al. 2009).

The cell-wall-related proteins can be categorized as proteins involved in (1) signal transduction, (2) synthesis, and (3) transport. Among the signal transduction proteins in Anabaena PCC 7120 , histidine kinases and protein phosphatases have recently been shown to act downstream of $\mathrm{NtcA}$ and have been suggested to be involved in heterocyst cell wall formation (Wang et al. 2002; Cheng et al. 2006). In Anabaena PCC 7120,131 genes encode putative histidine kinases, 52 genes code for serine/threonine and tyrosine kinases, and 13 genes code for a group of histidine and Ser/Thr hybrid (HSTKI) proteins (Ohmori et al. 2001; Phalip et al. 2001). Two genes, $p k n 30$ and $p k n 44$, that encode HSTKI proteins are involved in regulation of HGL2 synthesis (Shi et al. 2007). A single mutant of either kinase has no obvious phenotype, but a double mutant has an immature HEP layer and is defective in synthesis of the HGL2. PrpJ, a Ser/Thr phosphatase encoded by all1731, is involved in the regulation of the HGL1 (Jang et al. 2007).

Among the proteins that define cell wall structure, OmpA, encoded by all3289 and alr5049, acts as a physical linker between the outer membrane and the peptidoglycan layer. The alr1278gene encoding OstA/Imp is thought to be involved in remodeling of the lipid content of the outer membrane during heterocyst development (Nicolaisen et al. 2009). OstA/Imp is involved in transport of lipid A to the cell surface (Bos et al. 2004). Expression analysis showed that alr1278 was up-regulated early following nitrogen deprivation (Ehira and Ohmori 2006b).

The outer membrane of Anabaena PCC 7120 includes integral membrane proteins and lipoproteins attached to the outer membrane by amino-terminal lipids (Nicolaisen et al. 2009). These proteins comprise porin-type proteins, proteins that define the cell wall structure, and proteins involved in transport and assembly (Nicolaisen et al. 2009). In Anabaena PCC 7120,
All4499 and All4550, which show homology with the outer membrane porin OprB of Pseudomonas aeruginosa, were identified in membranes of vegetative cells and were the most abundant outer membrane proteins in heterocysts (Moslavac et al. 2005; Moslavac et al. 2007b). Genome-wide expression analysis of genes after nitrogen deprivation showed an increase in expression of all4499 8 hours after nitrogen deprivation and a decrease in expression of all4550 24 hours after nitrogen depletion. In addition, ORF alr0834, classified as encoding a general porin, is up-regulated during the early stages of heterocyst differentiation (Ehira and Ohmori 2006b).

A large number of outer membrane proteins are involved in protein transport and assembly. all0406 encodes a protein with high similarity to autotransporters, which are Gramnegative extracellular proteins that are characterized by the ability to translocate themselves across the outer membrane (Nicolaisen et al. 2009). HgdD, a TolC like protein, is an outer membrane efflux channel and functions in HGL-layer assembly. The $h g d D$ gene is up-regulated during heterocyst development and the protein is essential for HGL-layer formation. A $h g d D$ knockout mutant is defective in deposition of the HGL layer and the phenotype is similar to the defect observed for a $\operatorname{dev} B C A$ knockout. These data suggest the formation of a DevBCA-HgdD secretion complex that is essential for the formation of the HGL layer (Moslavac et al. 2007a).

\section{Nitrogen Fixation in Heterocysts}

Heterocyst development culminates with nitrogen fixation, which is the ATP-dependent process of reducing atmospheric nitrogen to ammonia by the enzyme nitrogenase. In many heterocystforming cyanobacteria, including Anabaena PCC 7120, nitrogenase is synthesized only in heterocysts, where it is protected from irreversible inactivation by oxygen (Fay 1992). However, some heterocyst-forming cyanobacteria contain an additional set of nif genes that allows nitrogen fixation in vegetative cells under anoxic conditions (Thiel et al. 1995). Nitrogenase is a 
well-conserved enzyme in all nitrogen-fixing organisms and consists of two components: dinitrogenase (Mo-Fe protein) and dinitrogenase reductase (Fe protein) (Rubio and Ludden 2008). Dinitrogenase reductase serves to transfer electrons from electron donors such as ferredoxin or flavodoxin to dinitrogenase. In Anabaena sp. PCC 7120, the $f d x H$ gene codes for a heterocyst-specific ferredoxin (Masepohl et al. 1997). In addition to the common molybdenum nitrogenase, some cyanobacteria contain an alternative nitrogenase that uses a vanadium cofactor (Pratte et al. 2006).

In Anabaena PCC 7120, the nitrogen-fixation (nif) genes are expressed specifically in heterocysts late during development, between 18 and 24 hours after nitrogen deprivation (Elhai and Wolk 1990; Golden et al. 1991). The nifHDK operon encodes the molybdenumcontaining nitrogenase enzyme complex. Upstream of the nifHDK operon is another nif operon, nifB-fdxN-nifS-nifU (Mulligan and Haselkorn 1989). The nifVZT genes form a nif gene cluster separated from the main nif gene cluster (Stricker et al. 1997). Other cyanobacterial nif genes include nifE, nif $N$, nifX, and nifW (Wolk et al. 1994; Thiel et al. 1995). The transcriptional regulators that control the expression of the nif genes in cyanobacteria have not been identified.

A heterocyst-specific uptake hydrogenase, encoded by the hupSL operon, recovers reductant from $\mathrm{H}_{2}$ produced by nitrogenase (Tamagnini et al. 2007). In Nostoc punctiforme, the upstream region of the hupSL operon contains an NtcA binding site and NtcA binds to the hupSL promoter in vitro, but deletion of the binding site did not affect the expression of hupSL significantly (Holmqvist et al. 2009). This study showed that sequences required for heterocyst-specific expression of the hupSL genes are located in a region starting 57 base pairs upstream of the transcription start point and extending 258 base pairs downstream. Whereas NtcA is not required for transcriptional regulation of hupSL in N. punctiforme, $\mathrm{NtcA}$ is required for the induction of hupSL in Anabaena variabilis after nitrogen step-down, as shown by reduced induction of hupSL in an $n t c A$ mutant (Weyman et al. 2008). A consensus NtcA-binding site is upstream of the A. variabilis hupSL operon, and NtcA binds to this region (Weyman et al. 2008).

Heterocyst development is accompanied by changes in the photosynthetic apparatus and carbon metabolism to provide ATP and low potential reductant for nitrogen fixation (Wolk et al. 1994; Meeks and Elhai 2002). Respiration by cytochrome coxidase generates ATP for nitrogen fixation and helps create the microoxic environment. Whereas cox 1 encoding mitochondrial type cytochrome c oxidase is expressed in vegetative cells, $\operatorname{cox} 2$ and $\operatorname{cox} 3$ are expressed only in heterocysts and are required for growth during nitrogen fixation (Jones and Haselkorn 2002; Valladares et al. 2003).

In Anabaena PCC 7120, three DNA rearrangements take place during the late stages of heterocyst development that affect nitrogen fixation and uptake hydrogenase operons (Golden et al. 1985; Golden et al. 1988; Carrasco et al. 1995; Carrasco and Golden 1995; Golden 1997; Carrasco et al. 2005). The rearrangements are the result of developmentally programmed sitespecific recombination between direct repeats that flank the DNA elements that are deleted from the chromosome (Golden 1997). One rearrangement excises an 11-kb element from the nifD gene (Golden et al. 1985; Brusca et al. 1989). The excision requires xisA located on the 11-kb element (Golden and Wiest 1988; Brusca et al. 1990; Lammers et al. 1990; Henson et al. 2008). A xisA null mutant forms heterocysts but is unable to excise the element or grow on media lacking a source of combined nitrogen (Golden and Wiest 1988; Golden et al. 1991). A second rearrangement excises a $55-\mathrm{kb}$ element from the $f d x N$ gene (Golden et al. 1988) and requires the xisF, xisH, and xisI genes (Carrasco et al. 1994; Ramaswamy et al. 1997). A third programmed DNA arrangement deletes a $10.5-\mathrm{kb}$ element from the $h u p L$ gene and requires the $x i s C$ recombinase gene (Carrasco et al. 1995; Carrasco et al. 2005). All three DNA elements appear to be parasitic DNA sequences that are passed to daughter vegetative cells as they are carried innocuously in genes that are only required in heterocysts. And, all three DNA elements have acquired the ability to 
excise from the chromosome in terminally differentiated heterocysts so that the genes in which they reside can be expressed. This developmental regulation has apparently evolved independently for each element but the regulatory mechanism is not yet known.

\section{RNA Polymerase $\sigma$ Factors are Developmentally Regulated}

The control of gene expression in bacteria is primarily regulated at the level of transcription initiation. Bacteria contain an RNA polymerase (RNAP) enzyme that requires an additional $\sigma$ factor for promoter recognition and transcription initiation. In many cases, a bacterium uses specific sigma $(\sigma)$ factors to activate a set of genes in response to environmental and intracellular signals (Campbell et al. 2008). For example, in Bacillus subtilis, temporally and spatially regulated $\sigma$ factors modulate the expression of genes during starvation-induced sporulation (Kroos 2007; Campbell et al. 2008). It was hypothesized that global changes in gene expression during heterocyst development in Anabaena PCC 7120 are regulated by $\sigma$ factors (Khudyakov and Golden 2001; Aldea et al. 2007). The $\sigma 70$ family of $\sigma$ factors has been divided into four major groups: Group 1 is responsible for transcription of housekeeping genes, group 2 is similar to group 1 but not essential under laboratory growth conditions, group 3 is involved in the expression of genes associated with sporulation, motility, stress response, and heat shock, and group 4 participates in multiple biological processes (Campbell et al. 2008). Anabaena PCC 7120 has 12 putative $\sigma$ factors identified by sequence similarity (Aldea et al. 2007; Yoshimura et al. 2007). Genetic analysis has not identified any $\sigma$ factor genes that are essential for heterocyst differentiation or nitrogen fixation, suggesting that there is a level of functional redundancy between the $\sigma$ factors (Khudyakov and Golden 2001).

Genetic analysis using $g f p$ as a reporter identified three $\sigma$-factor genes, $\operatorname{sig} C, \operatorname{sig} G$, and sigE, that are developmentally up-regulated after nitrogen deprivation (Aldea et al. 2007). The expression of $\operatorname{sig} C$ is up-regulated 4 hours after nitrogen step-down, and by 10 hours, the expression is restricted mostly to single cells in a heterocyst-like pattern (Fig. 4). SigC may be involved in regulating early heterocyst-specific genes (Aldea et al. 2007). The expression of sigE (alr4249) is low in vegetative cells grown in nitrate-containing media and is up-regulated in individual cells at about 16 hours after nitrogen depletion, suggesting that SigE may be involved in the expression of late heterocystspecific genes such as the nif and hup genes. Expression of a sigG reporter is seen in vegetative cells in media containing nitrate but decreases in all cells soon after nitrogen depletion. At around 9 hours after nitrogen stepdown, increased sig $G$ expression is localized to single cells and by 16 hours, expression is localized to morphologically distinguishable proheterocyst cells; at 24 hours, heterocysts show somewhat decreased reporter expression. These data suggest that SigG is involved in the expression of genes during the middle stages of differentiation such as those involved in morphogenesis and the creation of a microoxic environment, and possibly genes that are necessary for commitment to complete differentiation (Aldea et al. 2007).

\section{HETEROCYST PATTERN FORMATION REQUIRES DYNAMIC SIGNALING}

Pattern formation has been observed in many prokaryotic systems. For example, Myxococcus xanthus forms a complex three-dimensional pattern when starving bacteria self-organize to form fruiting bodies (Jelsbak and SøgaardAndersen 2002), and Pseudomonas aeruginosa produces biofilms during infection (Klausen et al. 2003). Temporary patterns have been studied in Escherichia coli and Salmonella typhimurium when these organisms swim in gradients of nutritional chemoattractant (Blair 1995; Budrene and Berg 1995). The developmentally regulated pattern of heterocysts in multicellular cyanobacteria offers a model to understand biological pattern formation, signals that control pattern formation, and downstream regulatory pathways. 
A longstanding model of heterocyst pattern formation is that differentiating cells produce an inhibitory signal that diffuses along a filament to form a gradient that inhibits differentiation of neighboring cells in a concentrationdependent manner (Wilcox et al. 1973; Wolk 1996). The patS gene in Anabaena PCC 7120 is essential for normal pattern formation and is predicted to encode a 13- to 17-amino-acid peptide depending on the start codon used in vivo (Fig. 5) (Yoon and Golden 1998; Yoon and Golden 2001). All filamentous cyanobacteria for which a genome sequence is available contain hetR and pat $S$ genes, and although the pat $S$ genes encode peptides from 13 to 90 amino acids, they all have an identical five amino acid sequence, RGSGR, at their carboxy-terminal ends (Zhang et al. 2009). This PatS pentapeptide sequence may be the essential element of the predicted diffusible inhibitor controlling, at least in part, heterocyst pattern.

The patS gene is transcribed early during heterocyst development. Expression analysis using northern RNA blots and a patS-lacZ reporter showed that pat $S$ is up-regulated by 6 hours after nitrogen deprivation (Yoon and Golden 1998). A patS-gfp reporter strain in nitrate-containing media showed low levels of expression in all cells. At 8-10 hours after nitrogen step-down, increased fluorescence was localized to small groups of cells or individual cells (Yoon and Golden 2001). By 12-14 hours after nitrogen step-down, most of the GFP signal was localized in individual cells that were arranged in a pattern similar to that of mature heterocysts, and by 18 hours, the fluorescence was localized almost entirely to heterocysts (also see Fig. 2).

A patS null mutant produces heterocysts even in the presence of nitrate, and forms multiple contiguous heterocysts after nitrogen deprivation with up to $30 \%$ of the cells differentiating to form heterocysts, whereas extra copies or overexpression of pat $S$ results in a complete suppression of heterocysts (Yoon and Golden 1998; Yoon and Golden 2001). Mutations in the last five carboxy-terminal residues of PatS result in a loss-of-function phenotype. A synthetic RGSGR pentapeptide, PatS-5, blocks heterocyst differentiation at nanomolar concentrations, whereas a four amino acid synthetic peptide did not inhibit differentiation (Yoon and Golden 1998). Addition of PatS-5 to growth medium of a patS null mutant at a concentration that decreases the frequency of heterocysts to the wild-type level does not restore a wild-type heterocyst pattern, but ectopic expression of patS from a heterocyst-specific promoter, hepA, in a patS null mutant background does restore the normal pattern. These data are consistent with PatS functioning as a diffusible inhibitor and that a gradient of PatS is required for the establishment of a normal pattern (Golden and Yoon 2003). However, other somewhat more complicated mechanisms are possible and direct support for this hypothesis would require, for example, the development of methods to detect gradients of small molecules in cyanobacterial filaments.

The PatS signal must move from differentiating cells to neighboring cells to inhibit HetR. However, a patS5 minigene expressed in heterocysts in a pat $S$ null background does not produce a normal pattern, indicating that PatS-5 produced by the minigene cannot function as a cell-to-cell signal and may remain in the cytoplasm of the differentiated cell, possibly because of the lack of a domain that is needed for transport to adjacent cells or export to the periplasmic space (Wu et al. 2004). The ability of large peptides containing an internal RGSGR sequence motif to inhibit heterocyst development supports the idea that the receptor for PatS is localized in the cytoplasm (Wu et al. 2004). In vitro studies show that the DNA-binding activity of HetR is inhibited by PatS- 5 pentapeptide in a dose-dependent manner, implying that the HetR-PatS ratio is important for controlling heterocyst differentiation and indicating that HetR is a PatS receptor (Huang et al. 2004). Up-regulation of hetR expression is abolished when PatS-5 is added to the growth medium (Huang et al. 2004). hetR mutant het $R_{\mathrm{R} 223 \mathrm{~W}}$ is insensitive to the PatS inhibitory signal and overexpression of the het $R_{\mathrm{R} 223 \mathrm{~W}}$ allele results in a conditionally lethal phenotype after nitrogen deprivation because nearly all cells differentiate (Khudyakov and Golden 2004). 
Overexpression of patS and hetR in a synthetic operon inhibits heterocyst formation, indicating that patS acts downstream of hetR, which is consistent with PatS inhibiting the activity of HetR (Orozco et al. 2006).

The het $N$ gene encodes a protein similar to ketoacyl reductase. Like patS, overexpression of het $N$ gene results in complete suppression of heterocyst development (Fig. 5). A het $N$ null mutant shows a wild-type pattern at 24 hours after nitrogen depletion but forms multiple contiguous heterocysts by 48 hours, suggesting that het $N$ is not necessary for de novo heterocyst pattern, and instead is required for the maintenance of the preexisting heterocyst pattern (Callahan and Buikema 2001). A patS-hetN double mutant shows complete differentiation of heterocysts in the absence of combined nitrogen, producing a lethal phenotype. These data indicate that the two inhibitory signal pathways may be independent (Borthakur et al. 2005). Together, patS- and het N-mediated inhibitory pathways are the primary mechanism for establishing heterocyst pattern.

However, other factors can influence pattern formation, such as the cell cycle, the physiology of individual cells, signals or nutrients from vegetative cells, and the products of nitrogen fixation (Golden and Yoon 2003; Sakr et al. 2006; Aldea et al. 2008). It is known that single cells from fragmented filaments will not differentiate but instead always divide first, followed by differentiation of one of the daughter cells, and it has been suggested that an activator, possibly 2-oxoglutarate, of differentiation is produced by vegetative cells and serves as a regulator of pattern formation (Zhao and Wolk 2008). There is some evidence for the products of nitrogen fixation supplied from heterocysts contributing to the average spacing between heterocysts along filaments (Yoon and Golden 2001; Aldea et al. 2008). However, data from A. variabilis, which can fix nitrogen in vegetative cells, have been interpreted as an argument against the products of nitrogen fixation having a significant effect on heterocyst pattern (Thiel and Pratte 2001). This seemingly simple question has been difficult to answer because mutants in which heterocysts cannot supply nitrogen to the filament cannot grow diazotrophically, which makes determining the maintenance of heterocyst pattern impossible.

In $N$. punctiforme, the novel genes pat $U$ and pat $N$ are required to inhibit excess heterocyst differentiation (Meeks et al. 2002). In Anabaena PCC 7120, a cluster of genes that influence pattern formation and heterocyst differentiation, het $Z$, pat U5, and pat U3, is conserved among heterocyst- and nonheterocyst-forming filamentous cyanobacteria (Zhang et al. 2007). All three genes are up-regulated after nitrogen deprivation and encode proteins with unknown function. A het $Z$ mutant does not differentiate heterocysts, unlike a patU3 mutant, which forms multiple contiguous heterocysts. When patU3 is inactivated in a patA mutant background, the patA mutant phenotype is abolished, restoring the formation of intercalary heterocysts (Zhang et al. 2007). Although these genes are clearly involved in the regulation of heterocyst development, their biochemical functions remain to be determined.

\section{CONCLUDING REMARKS}

Cyanobacteria have evolved several differentiated cell types in addition to heterocysts, including akinetes and the cells of hormogonia, to perform specialized functions. In N. punctiforme, vegetative cells have three developmental fates: heterocysts, akinetes, and hormogonial cells (Meeks et al. 2001; Meeks et al. 2002). Akinetes are perennating sporelike cells formed to endure cold and desiccation. Heterocysts and akinetes show pattern formation that must be regulated by cell-to-cell communication between cells within a filament. In the absence of heterocysts, akinetes form at random positions along a filament, whereas the presence of heterocysts influences akinete placing. In some organisms, akinetes differentiate from cells immediately adjacent to heterocysts, and in others chains of akinetes are produced in which the youngest are furthest away from the heterocysts. Hormogonia are typically short filaments of differentiated cells that lack heterocysts and often express gas vesicles and show gliding motility. One role of hormogonia is 
to disperse and inhabit new environments (Tandeau de Marsac 1994; Meeks and Elhai 2002). Although our knowledge of these additional forms of cyanobacterial development are limited compared with our understanding of heterocyst development, it is evident that cyanobacteria are capable of striking and complex multicellular development that involves the integration of environmental, extracellular, and intracellular signals to control cellular differentiation and morphogenesis. The study of multicellular developmental biology in cyanobacteria, as well as other bacterial developmental systems, has uprooted the common misconception of bacterial organisms as simple autonomous single cells.

\section{ACKNOWLEDGMENTS}

We thank anonymous reviewers for their comments and suggestions that helped improve this article. Preparation of this article was partially supported by award 0925126 from the National Science Foundation to J.W.G.

\section{REFERENCES}

Aldea MR, Kumar K, Golden JW. 2008. Heterocyst development and pattern formation. In Chemical communication among bacteria (ed. W.W. C. and B.L. Bassler), pp. 75-90. ASM Press, Washington, DC.

Aldea MR, Mella-Herrera RA, Golden JW. 2007. $\sigma$ factor genes $\operatorname{sig} C$, sigE, and $\operatorname{sig} G$ are upregulated in heterocysts of the cyanobacterium Anabaena sp. strain PCC 7120. J Bacteriol 189: 8392-8396.

Awai K, Wolk CP. 2007. Identification of the glycosyl transferase required for synthesis of the principal glycolipid characteristic of heterocysts of Anabaena sp. strain PCC 7120. FEMS Microbiol Lett 266: 98-102.

Awai K, Lechno-Yossef S, Wolk CP. 2009. Heterocyst Envelope Glycolipids. In Lipids in photosynthesis: essential and regulatory functions (ed. H. Wada and N. Murata), pp. 179-202. Springer, New York.

Black K, Buikema WJ, Haselkorn R. 1995. The $h g l K$ gene is required for localization of heterocyst-specific glycolipids in the cyanobacterium Anabaena sp. strain PCC 7120. J Bacteriol 177: 6440-6448.

Black TA, Cai Y, Wolk CP. 1993. Spatial expression and autoregulation of hetR, a gene involved in the control of heterocyst development in Anabaena. Mol Microbiol 9: $77-84$.

Blair DF. 1995. How bacteria sense and swim. Annu Rev Microbiol 49: 489-522.
Borthakur PB, Orozco CC, Young-Robbins SS, Haselkorn R, Callahan SM. 2005. Inactivation of patS and het $N$ causes lethal levels of heterocyst differentiation in the filamentous cyanobacterium Anabaena sp. PCC 7120. Mol Microbiol 57: 111-123.

Bos MP, Tefsen B, Geurtsen J, Tommassen J. 2004. Identification of an outer membrane protein required for the transport of lipopolysaccharide to the bacterial cell surface. Proc Natl Acad Sci 101: 9417-9422.

Brusca JS, Chastain CJ, Golden JW. 1990. Expression of the Anabaena sp. strain PCC 7120 xisA gene from a heterologous promoter results in excision of the nifD element. J Bacteriol 172: 3925-3931.

Brusca JS, Hale MA, Carrasco CD, Golden JW. 1989. Excision of an 11-kilobase-pair DNA element from within the nifD gene in Anabaena variabilis heterocysts. J Bacteriol 171: 4138-4145.

Budrene EO, Berg HC. 1995. Dynamics of formation of symmetrical patterns by chemotactic bacteria. Nature 376: 49-53.

Buikema WJ, Haselkorn R. 1991a. Characterization of a gene controlling heterocyst differentiation in the cyanobacterium Anabaena 7120. Genes Dev 5: 321-330.

Buikema WJ, Haselkorn R. 1991b. Isolation and complementation of nitrogen fixation mutants of the cyanobacterium Anabaena sp. strain PCC 7120. J Bacteriol 173: 1879-1885.

Buikema WJ, Haselkorn R. 2001. Expression of the Anabaena hetR gene from a copper-regulated promoter leads to heterocyst differentiation under repressing conditions. Proc Natl Acad Sci 98: 2729-2734.

Cai Y, Wolk CP. 1997. Nitrogen deprivation of Anabaena sp. strain PCC 7120 elicits rapid activation of a gene cluster that is essential for uptake and utilization of nitrate. J Bacteriol 179: 258-266.

Callahan SM, Buikema WJ. 2001. The role of HetN in maintenance of the heterocyst pattern in Anabaena sp. PCC 7120. Mol Microbiol 40: 941-950.

Campbell EL, Cohen MF, Meeks JC. 1997. A polyketidesynthase-like gene is involved in the synthesis of heterocyst glycolipids in Nostoc punctiforme strain ATCC 29133. Arch Microbiol 167: 251-258.

Campbell EA, Westblade LF, Darst SA. 2008. Regulation of bacterial RNA polymerase $\sigma$ factor activity: A structural perspective. Curr Opin Microbiol 11: 121-127.

Campbell EL, Summers ML, Christman H, Martin ME, Meeks JC. 2007. Global gene expression patterns of Nostoc punctiforme in steady-state dinitrogen-grown heterocyst-containing cultures and at single time points during the differentiation of akinetes and hormogonia. J Bacteriol 189: 5247-5256.

Cardemil L, Wolk CP. 1979. The polysaccharides from heterocyst and spore envelopes of a blue-green alga. Structure of the basic repeating unit. J Biol Chem 254: 736-741.

Cardemil L, Wolk CP. 1981. Isolated heterocysts of Anabaena variabilis synthesize envelope polysaccharide. Biochim Biophys Acta 674: 265-276.

Carrasco CD, Golden JW. 1995. Two heterocyst-specific DNA rearrangements of nif operons in Anabaena cylindrica and Nostoc sp. strain Mac. Microbiology 141: 2479-2487. 
Carrasco CD, Buettner JA, Golden JW. 1995. Programmed DNA rearrangement of a cyanobacterial hupL gene in heterocysts. Proc Natl Acad Sci 92: 791-795.

Carrasco CD, Holliday SD, Hansel A, Lindblad P, Golden JW. 2005. Heterocyst-specific excision of the Anabaena sp. strain PCC 7120 hupL element requires xisC. J Bacteriol 187: 6031-6038.

Carrasco CD, Ramaswamy KS, Ramasubramanian TS, Golden JW. 1994. Anabaena xisF gene encodes a developmentally regulated site-specific recombinase. Genes Dev 8: 74-83.

Chen H, Laurent S, Bédu S, Ziarelli F, Chen HL, Cheng Y, Zhang CC, Peng L. 2006. Studying the signaling role of 2-oxoglutaric acid using analogs that mimic the ketone and ketal forms of 2-oxoglutaric acid. Chem Biol 13: 849-856.

Cheng Y, Li JH, Shi L, Wang L, Latifi A, Zhang CC. 2006. A pair of iron-responsive genes encoding protein kinases with a Ser/Thr kinase domain and a His kinase domain are regulated by NtcA in the cyanobacterium Anabaena sp. strain PCC 7120. J Bacteriol 188: 4822-4829.

Cumino AC, Marcozzi C, Barreiro R, Salerno GL. 2007. Carbon cycling in Anabaena sp. PCC 7120. Sucrose synthesis in the heterocysts and possible role in nitrogen fixation. Plant Physiol 143: 1385-1397.

Dismukes GC, Carrieri D, Bennette N, Ananyev GM, Posewitz MC. 2008. Aquatic phototrophs: Efficient alternatives to land-based crops for biofuels. Curr Opin Biotechnol 19: 235-240.

Dong Y, Huang X, Wu XY, Zhao J. 2000. Identification of the active site of HetR protease and its requirement for heterocyst differentiation in the cyanobacterium Anabaena sp. strain PCC 7120. J Bacteriol 182: 1575-1579.

Ehira S, Ohmori M. 2006a. NrrA directly regulates the expression of het $R$ during heterocyst differentiation in the cyanobacterium Anabaena sp. strain PCC 7120 J Bacteriol 188: 8520-8525.

Ehira S, Ohmori M. 2006b. NrrA, a nitrogen-responsive response regulator facilitates heterocyst development in the cyanobacterium Anabaena sp. strain PCC 7120. Mol Microbiol 59: 1692-1703.

Ehira S, Ohmori M, Sato N. 2003. Genome-wide expression analysis of the responses to nitrogen deprivation in the heterocyst-forming cyanobacterium Anabaena sp. strain PCC 7120. DNA Res 10: 97-113.

Elhai J, Wolk CP. 1990. Developmental regulation and spatial pattern of expression of the structural genes for nitrogenase in the cyanobacterium Anabaena. EMBO J 9: 3379-3388.

Fan Q, Huang G, Lechno-Yossef S, Wolk CP, Kaneko T, Tabata S. 2005. Clustered genes required for synthesis and deposition of envelope glycolipids in Anabaena sp. strain PCC 7120. Mol Microbiol 58: 227-243.

Fay P. 1992. Oxygen relations of nitrogen fixation in cyanobacteria. Microbiol Rev 56: 340-373.

Fiedler G, Arnold M, Hannus S, Maldener I. 1998. The DevBCA exporter is essential for envelope formation in heterocysts of the cyanobacterium Anabaena sp. strain PCC 7120. Mol Microbiol 27: 1193-1202.

Fiedler G, Muro-Pastor AM, Flores E, Maldener I. 2001 NtcA-dependent expression of the $\operatorname{dev} B C A$ operon, encoding a heterocyst-specific ATP-binding cassette transporter in Anabaena spp. J Bacteriol 183: 3795-3799.

Flores E, Herrero A, Wolk CP, Maldener I. 2006. Is the periplasm continuous in filamentous multicellular cyanobacteria? Trends Microbiol 14: 439-443.

Flores E, Pernil R, Muro-Pastor AM, Mariscal V, Maldener I, Lechno-Yossef S, Fan Q, Wolk CP, Herrero A. 2007. Septum-localized protein required for filament integrity and diazotrophy in the heterocyst-forming cyanobacterium Anabaena sp. strain PCC 7120. J Bacteriol 189: 3884-3890.

Forchhammer K. 2004. Global carbon/nitrogen control by PII signal transduction in cyanobacteria: From signals to targets. FEMS Microbiol Rev 28: 319-333.

Frias JE, Flores E, Herrero A. 1994. Requirement of the regulatory protein NtcA for the expression of nitrogen assimilation and heterocyst development genes in the cyanobacterium Anabaena sp. PCC 7120. Mol Microbiol 14: $823-832$.

Giddings TH, Staehelin LA. 1978. Plasma membrane architecture of Anabaena cylindrica: occurrence of microplasmodesmata and changes associated with heterocyst development and the cell cycle. Eur J Cell Biol 16: 235-249.

Giddings TH, Staehelin LA. 1981. Observation of microplasmodesmata in both heterocyst-forming and nonheterocyst forming filamentous cyanobacteria by freeze-fracture electron microscopy. Arch Microbiol 129: 295-298.

Golden JW. 1997. Programmed DNA rearrangements in cyanobacteria. In Bacterial genomes: Physical structure and analysis (ed. F.J. de Bruijn, J.R. Lupski and G. Weinstock), pp. 162-173. Chapman and Hall, New York.

Golden JW, Wiest DR. 1988. Genome rearrangement and nitrogen fixation in Anabaena blocked by inactivation of xisA gene. Science 242: 1421-1423.

Golden JW, Yoon HS. 1998. Heterocyst formation in Anabaena. Curr Opin Microbiol 1: 623-629.

Golden JW, Yoon HS. 2003. Heterocyst development in Anabaena. Curr Opin Microbiol 6: 557-563.

Golden JW, Robinson SJ, Haselkorn R. 1985. Rearrangement of nitrogen fixation genes during heterocyst differentiation in the cyanobacterium Anabaena. Nature 314: 419-423.

Golden JW, Whorff LL, Wiest DR. 1991. Independent regulation of nifHDK operon transcription and DNA rearrangement during heterocyst differentiation in the cyanobacterium Anabaena sp. strain PCC 7120. J Bacteriol 173: 7098-7105.

Golden JW, Carrasco CD, Mulligan ME, Schneider GJ, Haselkorn R. 1988. Deletion of a 55-kilobase-pair DNA element from the chromosome during heterocyst differentiation of Anabaena sp. strain PCC 7120. J Bacteriol 170: 5034-5041.

Hebbar PB, Curtis SE. 2000. Characterization of $\operatorname{devH}$, a gene encoding a putative DNA binding protein required for heterocyst function in Anabaena sp. strain PCC 7120 J Bacteriol 182: 3572-3581.

Henson BJ, Pennington LE, Watson LE, Barnum SR. 2008. Excision of the nifD element in the heterocystous cyanobacteria. Arch Microbiol 189: 357-366. 
K. Kumar, R.A. Mella-Herrera, and J.W. Golden

Herrero A, Muro-Pastor AM, Valladares A, Flores E. 2004 Cellular differentiation and the NtcA transcription factor in filamentous cyanobacteria. FEMS Microbiol Rev 28: 469-487.

Hoiczyk E, Hansel A. 2000. Cyanobacterial cell walls: News from an unusual prokaryotic envelope. J Bacteriol 182: 1191-1199.

Holmqvist M, Stensjö K, Oliveira P, Lindberg P, Lindblad P. 2009. Characterization of the hupSL promoter activity in Nostoc punctiforme ATCC 29133. BMC Microbiol 9: 54.

Huang X, Dong Y, Zhao J. 2004. HetR homodimer is a DNAbinding protein required for heterocyst differentiation, and the DNA-binding activity is inhibited by PatS. Proc Natl Acad Sci 101: 4848-4853.

Huang G, Fan Q, Lechno-Yossef S, Wojciuch E, Wolk CP, Kaneko T, Tabata S. 2005. Clustered genes required for the synthesis of heterocyst envelope polysaccharide in Anabaena sp. strain PCC 7120. J Bacteriol 187: $1114-$ 1123.

Jang J, Wang L, Jeanjean R, Zhang CC. 2007. PrpJ, a PP2C-type protein phosphatase located on the plasma membrane, is involved in heterocyst maturation in the cyanobacterium Anabaena sp. PCC 7120. Mol Microbiol 64: $347-358$.

Jelsbak L, Søgaard-Andersen L. 2002. Pattern formation by a cell surface-associated morphogen in Myxococcus xanthus. Proc Natl Acad Sci 99: 2032-2037.

Jones KM, Haselkorn R. 2002. Newly identified cytochrome $\mathrm{c}$ oxidase operon in the nitrogen-fixing cyanobacterium Anabaena sp. strain PCC 7120 specifically induced in heterocysts. J Bacteriol 184: 2491-2499.

Khudyakov IY, Golden JW. 2001. Identification and inactivation of three group $2 \sigma$ factor genes in Anabaena sp. strain PCC 7120. J Bacteriol 183: 6667-6675.

Khudyakov IY, Golden JW. 2004. Different functions of HetR, a master regulator of heterocyst differentiation in Anabaena sp. PCC 7120 can be separated by mutation. Proc Natl Acad Sci 101: 16040-16045.

Khudyakov I, Wolk CP. 1997. hetC, a gene coding for a protein similar to bacterial $\mathrm{ABC}$ protein exporters, is involved in early regulation of heterocyst differentiation in Anabaena sp. strain PCC 7120. J Bacteriol 179: 6971-6978.

Klausen M, Heydorn A, Ragas P, Lambertsen L, AaesJørgensen A, Molin S, Tolker-Nielsen T. 2003. Biofilm formation by Pseudomonas aeruginosa wild type, flagella and type IV pili mutants. Mol Microbiol 48: 1511-1524.

Kroos L. 2007. The Bacillus and Myxococcus developmental networks and their transcriptional regulators. Annu Rev Genet 41: 13-39.

Lammers PJ, McLaughlin S, Papin S, Trujillo-Provencio C, Ryncarz AJ 2nd. 1990. Developmental rearrangement of cyanobacterial nif genes: Nucleotide sequence, open reading frames, and cytochrome P-450 homology of the Anabaena sp. strain PCC 7120 nifD element. J Bacteriol 172: 6981-6990.

Laurent S, Chen H, Bedu S, Ziarelli F, Peng L, Zhang CC. 2005. Nonmetabolizable analogue of 2-oxoglutarate elicits heterocyst differentiation under repressive conditions in Anabaena sp. PCC 7120. Proc Natl Acad Sci 102: 9907-9912.
Lechno-Yossef S, Fan Q, Ehira S, Sato N, Wolk CP. 2006. Mutations in four regulatory genes have interrelated effects on heterocyst maturation in Anabaena sp. strain PCC 7120. J Bacteriol 188: 7387-7395.

Liang J, Scappino L, Haselkorn R. 1992. The patA gene product, which contains a region similar to CheY of Escherichia coli, controls heterocyst pattern formation in the cyanobacterium Anabaena 7120. Proc Natl Acad Sci 89: 5655-5659.

Liu D, Golden JW. 2002. hetL overexpression stimulates heterocyst formation in Anabaena sp. strain PCC 7120. J Bacteriol 184: 6873-6881.

Marcozzi C, Cumino AC, Salerno GL. 2009. Role of NtcA, a cyanobacterial global nitrogen regulator, in the regulation of sucrose metabolism gene expression in Anabaena sp. PCC 7120. Arch Microbiol 191: 255-263.

Mariscal V, Herrero A, Flores E. 2007. Continuous periplasm in a filamentous, heterocyst-forming cyanobacterium. Mol Microbiol 65: 1139-1145.

Martin-Figueroa E, Navarro F, Florencio FJ. 2000. The GS-GOGAT pathway is not operative in the heterocysts. Cloning and expression of $g l s F$ gene from the cyanobacterium Anabaena sp. PCC 7120. FEBS Lett 476: 282-286.

Masepohl B, Schölisch K, Görlitz K, Kutzki C, Böhme H. 1997. The heterocyst-specific $f d x H$ gene product of the cyanobacterium Anabaena sp. PCC 7120 is important but not essential for nitrogen fixation. Mol Gen Genet 253: $770-776$.

Meeks JC, Elhai J. 2002. Regulation of cellular differentiation in filamentous cyanobacteria in free-living and plant-associated symbiotic growth states. Microbiol Mol Biol Rev 66: 94-121.

Meeks JC, Campbell EL, Summers ML, Wong FC. 2002. Cellular differentiation in the cyanobacterium Nostoc punctiforme. Arch Microbiol 178: 395-403.

Meeks JC, Elhai J, Thiel T, Potts M, Larimer F, Lamerdin J, Predki P, Atlas R. 2001. An overview of the genome of Nostoc punctiforme, a multicellular, symbiotic cyanobacterium. Photosyn Res 70: 85-106.

Montoya JP, Holl CM, Zehr JP, Hansen A, Villareal TA, Capone DG. 2004. High rates of N2 fixation by unicellular diazotrophs in the oligotrophic Pacific Ocean. Nature 430: 1027-1032.

Moslavac S, Bredemeier R, Mirus O, Granvogl B, Eichacker LA, Schleiff E. 2005. Proteomic analysis of the outer membrane of Anabaena sp. strain PCC 7120. J Proteome Res 4: 1330-1338.

Moslavac S, Nicolaisen K, Mirus O, Al Dehni F, Pernil R, Flores E, Maldener I, Schleiff E. 2007a. A TolC-like protein is required for heterocyst development in Anabaena sp. strain PCC 7120. J Bacteriol 189: 7887-7895.

Moslavac S, Reisinger V, Berg M, Mirus O, Vosyka O, Ploscher M, Flores E, Eichacker LA, Schleiff E. 2007b. The proteome of the heterocyst cell wall in Anabaena sp. PCC 7120. Biol Chem 388: 823-829.

Mulligan ME, Haselkorn R. 1989. Nitrogen fixation (nif) genes of the cyanobacterium Anabaena species strain PCC 7120. The nifB-fdxN-nifS-nifU operon. J Biol Chem 264: 19200-19207.

Mullineaux CW, Mariscal V, Nenninger A, Khanum H, Herrero A, Flores E, Adams DG. 2008. Mechanism of 
intercellular molecular exchange in heterocyst-forming cyanobacteria. EMBO J 27: 1299-1308.

Muro-Pastor AM, Olmedo-Verd E, Flores E. 2006. All4312, an NtcA-regulated two-component response regulator in Anabaena sp. strain PCC 7120. FEMS Microbiol Lett 256: 171-177.

Muro-Pastor AM, Valladares A, Flores E, Herrero A. 1999. The hetC gene is a direct target of the NtcA transcriptional regulator in cyanobacterial heterocyst development. J Bacteriol 181: 6664-6669.

Muro-Pastor MI, Reyes JC, Florencio FJ. 2001. Cyanobacteria perceive nitrogen status by sensing intracellular 2-oxoglutarate levels. J Biol Chem 276: 38320-38328.

Muro-Pastor MI, Reyes JC, Florencio FJ. 2005. Ammonium assimilation in cyanobacteria. Photosynth Res 83: $135-150$.

Muro-Pastor AM, Valladares A, Flores E, Herrero A. 2002. Mutual dependence of the expression of the cell differentiation regulatory protein HetR and the global nitrogen regulator NtcA during heterocyst development. $\mathrm{Mol}$ Microbiol 44: 1377-1385.

Nayar AS, Yamaura H, Rajagopalan R, Risser DD, Callahan SM. 2007. FraG is necessary for filament integrity and heterocyst maturation in the cyanobacterium Anabaena sp. strain PCC 7120. Microbiology 153: 601-607.

Neunuebel MR, Golden JW. 2008. The Anabaena sp. strain PCC 7120 gene all2874 encodes a diguanylate cyclase and is required for normal heterocyst development under high-light growth conditions. J Bacteriol 190: 6829-6836.

Ni S, Sheldrick GM, Benning MM, Kennedy MA. 2009. The $2 \AA$ resolution crystal structure of HetL, a pentapeptide repeat protein involved in regulation of heterocyst differentiation in the cyanobacterium Nostoc sp. strain PCC 7120. J Struct Biol 165: 47-52.

Nicolaisen K, Hahn A, Schleiff E. 2009. The cell wall in heterocyst formation by Anabaena sp. PCC 7120. J Basic Microbiol 49: 5-24.

Ohmori M, Ikeuchi M, Sato N, Wolk P, Kaneko T, Ogawa T, Kanehisa M, Goto S, Kawashima S, Okamoto S, et al. 2001. Characterization of genes encoding multi-domain proteins in the genome of the filamentous nitrogenfixing cyanobacterium Anabaena sp. strain PCC 7120. DNA Res 8: 271-284.

Orozco CC, Risser DD, Callahan SM. 2006. Epistasis analysis of four genes from Anabaena sp. strain PCC 7120 suggests a connection between PatA and PatS in heterocyst pattern formation. J Bacteriol 188: 1808-1816.

Pereira S, Zille A, Micheletti E, Moradas-Ferreira P, De Philippis R, Tamagnini P. 2009. Complexity of cyanobacterial exopolysaccharides: Composition, structures, inducing factors and putative genes involved in their biosynthesis and assembly. FEMS Microbiol Rev 33: 917-941.

Phalip V, Li JH, Zhang CC. 2001. HstK, a cyanobacterial protein with both a serine/threonine kinase domain and a histidine kinase domain: Implication for the mechanism of signal transduction. Biochem J 360: 639-644.

Popa R, Weber PK, Pett-Ridge J, Finzi JA, Fallon SJ, Hutcheon ID, Nealson KH, Capone DG. 2007. Carbon and nitrogen fixation and metabolite exchange in and between individual cells of Anabaena oscillarioides. ISME J 1: 354-360.
Pratte BS, Eplin K, Thiel T. 2006. Cross-functionality of nitrogenase components NifH1 and VnfH in Anabaena variabilis. J Bacteriol 188: 5806-5811.

Ramasubramanian TS, Wei TF, Golden JW. 1994. Two Anabaena sp. strain PCC 7120 DNA-binding factors interact with vegetative cell- and heterocyst-specific genes. J Bacteriol 176: 1214-1223.

Ramasubramanian TS, Wei TF, Oldham AK, Golden JW. 1996. Transcription of the Anabaena sp. strain PCC 7120 ntcA gene: Multiple transcripts and NtcA binding. J Bacteriol 178: 922-926.

Ramaswamy KS, Carrasco CD, Fatma T, Golden JW. 1997. Cell-type specificity of the Anabaena $f d x N$-element rearrangement requires xisH and xisI. Mol Microbiol 23: 1241-1249.

Ramirez ME, Hebbar PB, Zhou R, Wolk CP, Curtis SE. 2005. Anabaena sp. strain PCC 7120 gene devH is required for synthesis of the heterocyst glycolipid layer. J Bacteriol 187: 2326-2331.

Risser DD, Callahan SM. 2007. Mutagenesis of hetR reveals amino acids necessary for HetR function in the heterocystous cyanobacterium Anabaena sp. strain PCC 7120. J Bacteriol 189: 2460-2467.

Risser DD, Callahan SM. 2008. HetF and PatA control levels of HetR in Anabaena sp. strain PCC 7120. J Bacteriol 190: $7645-7654$.

Rubio LM, Ludden PW. 2008. Biosynthesis of the ironmolybdenum cofactor of nitrogenase. Annu Rev Microbiol 62: 93-111.

Sakr S, Jeanjean R, Zhang CC, Arcondeguy T. 2006. Inhibition of cell division suppresses heterocyst development in Anabaena sp. strain PCC 7120. J Bacteriol 188: 1396-1404.

Sandh G, El-Shehawy R, Diez B, Bergman B. 2009. Temporal separation of cell division and diazotrophy in the marine diazotrophic cyanobacterium Trichodesmium erythraeum IMS101. FEMS Microbiol Lett 295: 281-288.

Sato N, Ohmori M, Ikeuchi M, Tashiro K, Wolk CP, Kaneko T, Okada K, Tsuzuki M, Ehira S, Katoh H, et al. 2004. Use of segment-based microarray in the analysis of global gene expression in response to various environmental stresses in the cyanobacterium Anabaena sp. PCC 7120. $J$ Gen Appl Microbiol 50: 1-8.

Shi L, Li JH, Cheng Y, Wang L, Chen WL, Zhang CC. 2007. Two genes encoding protein kinases of the HstK family are involved in synthesis of the minor heterocyst-specific glycolipid in the cyanobacterium Anabaena sp. strain PCC 7120. J Bacteriol 189: 5075-5081.

Shi Y, Zhao W, Zhang W, Ye Z, Zhao J. 2006. Regulation of intracellular free calcium concentration during heterocyst differentiation by HetR and NtcA in Anabaena sp. PCC 7120. Proc Natl Acad Sci 103: 11334-11339.

Stricker O, Masepohl B, Klipp W, Böhme H. 1997. Identification and characterization of the nifV-nifZ-nifT gene region from the filamentous cyanobacterium Anabaena sp. strain PCC 7120. J Bacteriol 179: 2930-2937.

Tamagnini P, Leitão E, Oliveira P, Ferreira D, Pinto F, Harris DJ, Heidorn T, Lindblad P. 2007. Cyanobacterial hydrogenases: Diversity, regulation and applications. FEMS Microbiol Rev 31: 692-720. 
Tandeau de Marsac N. 1994. Differentiation of hormogonia and relationships with other biological processes. In The molecular biology of cyanobacteria (ed. D.A. Bryant), pp. 825-840. Kluwer Academic Publishers, Dordrecht.

Tanigawa R, Shirokane M, Maeda Si S, Omata T, Tanaka K, Takahashi H. 2002. Transcriptional activation of NtcAdependent promoters of Synechococcus sp. PCC 7942 by 2-oxoglutarate in vitro. Proc Natl Acad Sci 99: 42514255.

Thiel T, Pratte B. 2001. Effect on heterocyst differentiation of nitrogen fixation in vegetative cells of the cyanobacterium Anabaena variabilis ATCC 29413. J Bacteriol 183: 280-286.

Thiel T, Lyons EM, Erker JC, Ernst A. 1995. A second nitrogenase in vegetative cells of a heterocyst-forming cyanobacterium. Proc Natl Acad Sci 92: 9358-9362.

Toepel J, Welsh E, Summerfield TC, Pakrasi HB, Sherman LA. 2008. Differential transcriptional analysis of the cyanobacterium Cyanothece sp. strain ATCC 51142 during light-dark and continuous-light growth. J Bacteriol 190: 3904-3913.

Torrecilla I, Leganés F, Bonilla I, Fernández-Piñas F. 2004. A calcium signal is involved in heterocyst differentiation in the cyanobacterium Anabaena sp. PCC7120. Microbiology 150: 3731-3739.

Valladares A, Herrero A, Pils D, Schmetterer G, Flores E 2003. Cytochrome $c$ oxidase genes required for nitrogenase activity and diazotrophic growth in Anabaena sp. PCC 7120. Mol Microbiol 47: 1239-1249.

Valladares A, Muro-Pastor AM, Herrero A, Flores E. 2004 The NtcA-dependent P1 promoter is utilized for $g \ln A$ expression in $\mathrm{N}_{2}$-fixing heterocysts of Anabaena sp. strain PCC 7120. J Bacteriol 186: 7337-7343.

Vazquez-Bermúdez MF, Herrero A, Flores E. 2002. 2-Oxoglutarate increases the binding affinity of the NtcA (nitrogen control) transcription factor for the Synechococcus glnA promoter. FEBS Lett 512: 71-74.

Vazquez-Bermúdez MF, Herrero A, Flores E. 2003. Carbon supply and 2-oxoglutarate effects on expression of nitrate reductase and nitrogen-regulated genes in Synechococcus sp. strain PCC 7942. FEMS Microbiol Lett 221: 155-159.

Wang Y, Xu X. 2005. Regulation by het $C$ of genes required for heterocyst differentiation and cell division in Anabaena sp. strain PCC 7120. J Bacteriol 187: 8489-8493.

Wang L, Sun YP, Chen WL, Li JH, Zhang CC. 2002. Genomic analysis of protein kinases, protein phosphatases and two-component regulatory systems of the cyanobacterium Anabaena sp. strain PCC 7120. FEMS Microbiol Lett 217: 155-165.

Wang Y, Lechno-Yossef S, Gong Y, Fan Q, Wolk CP, Xu X. 2007. Predicted glycosyl transferase genes located outside the HEP island are required for formation of heterocyst envelope polysaccharide in Anabaena sp. strain PCC 7120. J Bacteriol 189: 5372-5378.

Wei TF, Ramasubramanian TS, Golden JW. 1994. Anabaena sp. strain PCC 7120 ntcA gene required for growth on nitrate and heterocyst development. J Bacteriol 176: 4473-4482.

Wei TF, Ramasubramanian TS, Pu F, Golden JW. 1993. Anabaena sp. strain PCC 7120 bifA gene encoding a sequence-specific DNA-binding protein cloned by in vivo transcriptional interference selection. J Bacteriol 175: 4025-4035.

Weyman PD, Pratte B, Thiel T. 2008. Transcription of hupSL in Anabaena variabilis ATCC 29413 is regulated by NtcA and not by hydrogen. Appl Environ Microbiol 74: 2103-2110.

Wilcox M, Mitchison GJ, Smith RJ. 1973. Pattern formation in the blue-green alga, Anabaena. I. Basic mechanisms. J Cell Sci 12: 707-723.

Wolk CP. 1996. Heterocyst formation. Annu Rev Genet 30: 59-78.

Wolk CP, Ernst A, Elhai J. 1994. Heterocyst metabolism and development. In The molecular biology of cyanobacteria (ed. D.A. Bryant), pp. 769-863. Kluwer Academic Publishers, Dordrecht.

Wolk CP, Cai Y, Cardemil L, Flores E, Hohn B, Murry M, Schmetterer G, Schrautemeier B, Wilson R. 1988. Isolation and complementation of mutants of Anabaena sp. strain PCC 7120 unable to grow aerobically on dinitrogen. J Bacteriol 170: 1239-1244.

Wong FC, Meeks JC. 2001. The hetF gene product is essential to heterocyst differentiation and affects HetR function in the cyanobacterium Nostoc punctiforme. J Bacteriol 183: 2654-2661.

Wu X, Lee DW, Mella RA, Golden JW. 2007. The Anabaena sp. strain PCC 7120 asr1734 gene encodes a negative regulator of heterocyst development. Mol Microbiol 64: $782-794$.

Wu X, Liu D, Lee MH, Golden JW. 2004. patS minigenes inhibit heterocyst development of Anabaena sp. strain PCC 7120. J Bacteriol 186: 6422-6429.

Xu X, Wolk CP. 2001. Role for hetC in the transition to a nondividing state during heterocyst differentiation in Anabaena sp. J Bacteriol 183: 393-396.

Yoon HS, Golden JW. 1998. Heterocyst pattern formation controlled by a diffusible peptide. Science 282: 935-938.

Yoon HS, Golden JW. 2001. PatS and products of nitrogen fixation control heterocyst pattern. J Bacteriol 183: 2605-2613.

Yoshimura H, Okamoto S, Tsumuraya Y, Ohmori M. 2007. Group $3 \sigma$ factor gene, sigJ, a key regulator of desiccation tolerance, regulates the synthesis of extracellular polysaccharide in cyanobacterium Anabaena sp. strain PCC 7120. DNA Res 14: 13-24.

Zhang JY, Chen WL, Zhang CC. 2009. hetR and patS, two genes necessary for heterocyst pattern formation, are widespread in filamentous nonheterocyst-forming cyanobacteria. Microbiology 155: 1418-1426.

Zhang LC, Chen YF, Chen WL, Zhang CC. 2008. Existence of periplasmic barriers preventing green fluorescent protein diffusion from cell to cell in the cyanobacterium Anabaena sp. strain PCC 7120. Mol Microbiol 70: 814-823.

Zhang W, Du Y, Khudyakov I, Fan Q, Gao H, Ning D, Wolk CP, $\mathrm{Xu}$ X. 2007. A gene cluster that regulates both heterocyst differentiation and pattern formation in Anabaena sp. strain PCC 7120. Mol Microbiol 66: 1429-1443.

Zhang CC, Laurent S, Sakr S, Peng L, Bédu S. 2006. Heterocyst differentiation and pattern formation in cyanobacteria: A chorus of signals. Mol Microbiol 59: 367-375.

Zhao J, Wolk CP. 2008. Developmental Biology of Heterocysts, 2006. In Myxobacteria: Multicellularity and differentiation 
(ed. D.E. Whitworth), pp. 397-418. ASM Press, Washington, DC.

Zhou R, Wolk CP. 2003. A two-component system mediates developmental regulation of biosynthesis of a heterocyst polysaccharide. J Biol Chem 278: 19939-19946.

Zhao Y, Shi Y, Zhao W, Huang X, Wang D, Brown N, Brand J, Zhao J. 2005. CcbP, a calcium-binding protein from Anabaena sp. PCC 7120, provides evidence that calcium ions regulate heterocyst differentiation. Proc Natl Acad Sci 102: $5744-5748$
Zhou R, Wei X, Jiang N, Li H, Dong Y, Hsi KL, Zhao J. 1998. Evidence that HetR protein is an unusual serine-type protease. Proc Natl Acad Sci 95: 4959-4963.

Zhu J, Kong R, Wolk CP. 1998. Regulation of hepA of Anabaena sp. strain PCC 7120 by elements 5' from the gene and by hepK. J Bacteriol 180: 4233-4242.

Zhu J, Jager K, Black T, Zarka K, Koksharova O, Wolk CP. 2001. HcwA, an autolysin, is required for heterocyst maturation in Anabaena sp. strain PCC 7120. J Bacterio 183: $6841-6851$. 


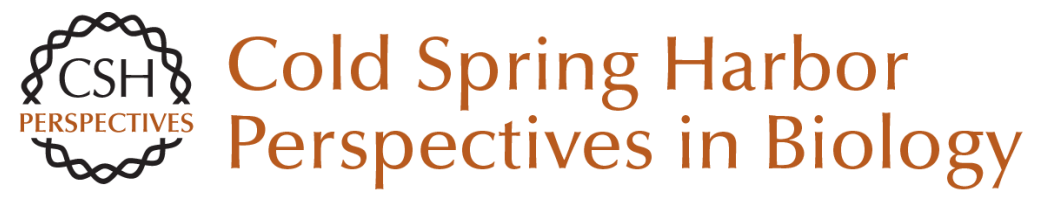

\section{Cyanobacterial Heterocysts}

Krithika Kumar, Rodrigo A. Mella-Herrera and James W. Golden

Cold Spring Harb Perspect Biol 2010; doi: 10.1101/cshperspect.a000315 originally published online February 24, 2010

\section{Subject Collection Cell Biology of Bacteria}

\section{Electron Cryotomography}

Elitza I. Tocheva, Zhuo Li and Grant J. Jensen

Protein Subcellular Localization in Bacteria David Z. Rudner and Richard Losick

Poles Apart: Prokaryotic Polar Organelles and Their Spatial Regulation

Clare L. Kirkpatrick and Patrick H. Viollier

Myxobacteria, Polarity, and Multicellular

Morphogenesis

Dale Kaiser, Mark Robinson and Lee Kroos

Membrane-associated DNA Transport Machines Briana Burton and David Dubnau

The Bacterial Cell Envelope

Thomas J. Silhavy, Daniel Kahne and Suzanne Walker

Cell Biology of Prokaryotic Organelles Dorothee Murat, Meghan Byrne and Arash Komeili

Bacterial Chromosome Organization and

\section{Segregation}

Esteban Toro and Lucy Shapiro
Cyanobacterial Heterocysts

Krithika Kumar, Rodrigo A. Mella-Herrera and James W. Golden

Synchronization of Chromosome Dynamics and

Cell Division in Bacteria Martin Thanbichler

Automated Quantitative Live Cell Fluorescence

Microscopy

Michael Fero and Kit Pogliano

The Structure and Function of Bacterial Actin

Homologs Joshua W. Shaevitz and Zemer Gitai

\section{Biofilms}

Daniel López, Hera Vlamakis and Roberto Kolter

Bacterial Nanomachines: The Flagellum and Type

III Injectisome

Marc Erhardt, Keiichi Namba and Kelly T. Hughes

Single-Molecule and Superresolution Imaging in Live Bacteria Cells Julie S. Biteen and W.E. Moerner

For additional articles in this collection, see http://cshperspectives.cshlp.org/cgi/collection/

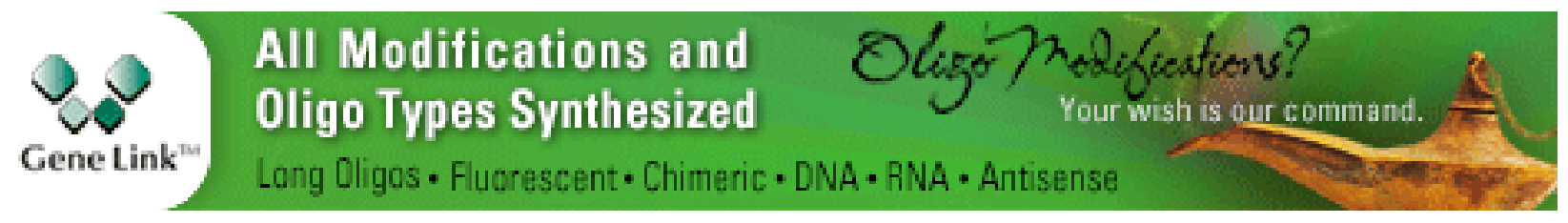

Copyright @ 2010 Cold Spring Harbor Laboratory Press; all rights reserved 